\title{
Peningkatan Persepsi Mahasiswa Terhadap Radikalisme di Era Globalisasi Melalui Mata Kuliah Pendidikan Pancasila
}

\author{
Ninik Sri Rahayu Wilujenga, ${ }^{a}$, Asmaul Khusna ${ }^{\mathrm{b}, 2}$ \\ a,bProgram Studi Teknologi Pengolahan Hasil Ternak, Politeknik Negeri Banyuwangi \\ Ininikrahayu@poliwangi.ac.id; 2akhusna@poliwangi.ac.id \\ *korespondensi penulis
}

Naskah diterima: 16-08-2018, direvisi: 24-08-2018, disetujui: 03-09-2018

DOI: http://dx.doi.org/10.32493/jpkn.v5i2.y2018.p97-106

\begin{abstract}
Abstrak
Paham radikalisme dapat memecah belah persatuan dan kesatuan bangsa Indonesia dan dapat menghancurkan ideologi Negara. Permasalahan radikalisme di era globalisasi ini yaitu radikalisme agama. Setelah menempuh mata kuliah Pendidikan Pancasila khususnya Ideologi Pancasila, mahasiswa diharapkan mampu memahami radikalisme lebih baik sehingga dapat menangkal adanya radikalisme yang beredar di kampus. Tujuan dari mata kuliah Pendidikan Pancasila pada perguruan tinggi, khususnya pokok bahasan Pancasila Sebagai Ideologi Negara yaitu pengembangan karakter Pancasilais yang teraktualisasi dalam sikap jujur, tanggung jawab, santun, ramah lingkungan, gotong royong, dan cinta damai. Pada Penelitian ini dilakukan tes mengenai persepsi mahasiswa mengenai paham radikalisme sebelum dan sesudah pembelajaran mata kuliah Pendidikan Pancasila. Pengukuran persepsi mahasiswa menggunakan kuesioner skala likert dengan lima belas butir item. Kuesioner terbagi menjadi tiga aspek yaitu definisi radikalisme, tujuan radikalisme, akibat adanya radikalime. Kuesioner tersebut diklasifikasikan ke dalam mahasiswa yang memiliki pemahaman yang sangat baik, baik, dan cukup. Dari kedua tes tersebut diketahui adanya pengaruh Pendidikan Pancasila terhadap persepsi mahasiswa mengenai radikalisme. Setelah perkuliahan Pendidikan Pancasila, persepsi mahasiswa dalam kategori yang sama, memiliki peningkatan nilai.
\end{abstract}

Kata-kata kunci: Persepsi Mahasiswa, Radikalisme, Pendidikan Pancasila

\section{Abstract}

The problem of radicalism in this globalization era is especially religious radicalism. After The students learn the Pancasila Education course in Ideology Pancasila topic, students are expected to be able to understand radicalism so that it can counteract the radicalism circulating in campus. The purpose of the Pancasila Education course in higher education, especially the subject of Pancasila as a State Ideology that is develops the Pancasila character. They are actualized in an honest, responsible, polite, friendly with their enviroment, mutual cooperation, and peace-loving attitude. In this research, tests were carried out on students' perceptions of radicalism. It was done before and after learning the Pancasila Education course. Measurement of student perceptions use a Likert scale questionnaire with fifteen items. The questionnaire is divided into three aspects, namely the definition of radicalism, the purpose of radicalism, due to radicalism. Moreover, the questionnaire is classified into students who have very good, good, and sufficient understanding. From the two tests, it has result that there was an influence of Pancasila Education on students' perceptions of radicalism. After the Pancasila Education course, the perception of students in the same category get increase in total value.

Keywords: Perceptions of Students, Radicalism, Pancasila Education 


\section{Pendahuluan}

Pancasila merupakan ideologi dan dasar Negara Republik Indonesia. Mata kuliah Pendidikan Pancasila merupakan pelajaran yang memberikan pemahaman kepada setiap insan untuk mengkaji, menganalisis, dan memecahkan masalahmasalah pembangunan bangsa dan Negara dalam perspektif nilai-nilai dasar Pancasila sebagai Ideologi dan Dasar Negara Kesatuan Republik Indonesia (Tim Penyusun, 2013). Pada dewasa ini di Era Globalisasi ideologi berkembang ke dalam kehidupan yang lebih luas seperti ideologi pasar dan ideologi agama.Ideologi agama berkembang kearah radikalisme agama. Sedangkan kampus merupakan ranah publik dengan mahasiswa dan aluminya yang dapat menjadi sasaran berbagai pengaruh serta infiltrasi paham, wacana, dan gerakan radikalisme agama dari luar. Oleh karena itu sangatlah penting memberikan pemahaman mengenai radikalisme pada mahasiswa agar mahasiswa dapat memiliki jiwa Pancasilais sehingga paham radikalisme tidak dapat memecah belah persatuan dan kesatuan Bangsa Indonesia.

Pemahaman mengenai radikalisme diberikan kepada mahasiswa pada mata kuliah Pendidikan Pancasila khususnya pokok bahasan Pancasila sebagai Ideologi Negara. Setelah mempelajari pokok bahasan tersebut mahasiswa dapat mengembangkan karakter Pancasilais yang teraktualisasi dalam sikap jujur, tanggung jawab, tanggung jawab, santun, ramah lingkungan, gotong royong, dan cinta damai (Dirjen Pembelajaran, 2016).
Hal tersebut sesuai dengan tujuan mata kuliah Pendidikan Pancasila. Untuk dapat mengetahui bagaimana hubungan antara pembelajaran Pendidikan Pancasila dan persepsi mahasiswa maka akan dilakukan bentuk pembelajaran yang interaktif dalam mata kuliah Pendidikan Pancasila.

Pendidikan Pancasila di Perguruan Tinggi adalah membangun semangat bela Negara pada para mahasiswa sebagai kader-kader bangsa serta memiliki tanggung jawab kemanusiaan dalam rangka menjamin kelangsungan hidup bangsa dan Negara Republik Indonesia berdasarkan Pancasila dan UUD 1945. Pendidikan Pancasila diterapkan dalam rangka pelaksanaan UU No.20 Tahun 2003 tentang sistem pendidikan nasional. Serta didukung UU No.12 Tahun 2012 yang memiliki tujuan mahasiswa diharapkan memiliki kemampuan hardskill dan softskill yaitu menjadi manusia yang beriman dan bertakwa kepada Tuhan YME, dan berakhlak mulia, sehat, berilmu, cakap, kreatif, mandiri, terampil, kompeten, dan berbudaya untuk kepentingan bangsa. Untuk mewujudkan tujuan tersebut Direktorat Pembelajaran dan Kemahasiswaan mewajibkan mata kuliah dasar umum (MKDU) pada perguruan tinggi, salah satunya Pendidikan Pancasila (Tim Penyusun, 2013).

Sejalan dengan revolusi karakter dalam nawacita, mata kuliah wajib umum (MKWU) di perguruan tinggi menjadi sumber nilai dan pedoman penyelenggaraan program studi yang mengantarkan mahasiswa memantapkan kepribadiannya agar konsisten 
mewujudkan nilai-nilai dasar keagamaan dan kebudayaan, serta rasa cinta tanah air dan bangsa. Pembelajaran yang terdapat pada MKWU berpusat pada mahasiswa. Ada beberapa pokok bahasan dalam Pendidikan Pancasila yaitu Pancasila sebagai dasar Negara, Pancasila sebagai Ideologi Negara, Pancasila sebagai sistem filsafat, Pancasila sebagai sistem etika, Pancasila sebagai dasar pengembangan ilmu (Dirjen Pembelajaran dan Kemahasiswaan, 2016).

Pada Penelitian ini akan dilakukan tes mengenai persepsi mahasiswa mengenai paham radikalisme sebelum dan sesudah pembelajaran. Tes ini menggunakan skala likert dengan skor 1 sampai 4 . Kemudian diklasifikasikan kedalam mahasiswa yang memiliki pemahaman yang sangat baik, baik, dan cukup terhadap definisi radikalisme, tujuan radikalisme, akibat adanya radikalime. Dari kedua tes tersebut dapat diketahui apakah ada perubahan persepsi mahasiswa mengenai radikalisme sebelum dan sesudah menempuh Pendidikan Pancasila.

Untuk mengukur persepsi mahasiswa mengenai radikalisme menggunakan kesioner dengan skala likert dan observasi pada saat pembelajaran. Suatu skala adalah alat pengukuran yang menyediakan tugas tentang simbol atau angka terhadap individu atau tingkah laku dengan aturan tertentu (Subhan, 2005). Skala yang digunakan dalam penelitian ini adalah modifikasi skala Likert dengan empat tingkatan yaitu sangat setuju (SS), setuju (S), tidak setuju (TS), dan sangat tidak setuju (STS). Pemilihan skala
Likert dikarenakan skala Likert mudah digunakan dalam pengukuran ranah psikomotorik sedangkan pemilihan empat tingkatan dengan pertimbangan agar jawaban siswa tidak cenderung ditengah. Untuk pemberian skor pernyataan positif tingkatan SS diberi skor 4, S diberi skor 3, TS diberi skor 2, STS diberi skor 1, dan untuk pernyataan negatif tingkatan STS diberi skor 4, TS diberi skor 3, S diberi skor 2, SS diberi skor 1. Hal tersebut sesuai pendapat Sukardi (2004) yang mengemukakan bahwa ada kecenderungan seseorang atau responden memberikan jawaban pada tingkatan tengah jika tingkatannya berjumlah ganjil, sehingga peneliti tidak memperoleh informasi pasti.

\section{Metode}

Metode yang digunakan dalam penelitian ini adalah metode penelitian deskriptif kausalitas yang digabungkan dengan PTK dimana terdapat pendekatan kualitatif yang hasilnya ditunjang oleh data kuantitatif dan analisis data yang dilakukan bersifat deskriptif. Penelitian menggunakan metode deskripsi kualitatif untuk mengetahui hubungan sedangkan untuk PTK digunakan untuk proses pembelajaran Pendidikan Pancasila. Hasil dari setiap siklus yang dilakukan pada mahasiswa akan dibandingkan dengan sasaran tindakan, dan akan dijadikan bahan untuk perbaikan tindakan-tindakan yang dianggap kurang sehingga dapat dijadikan alat evaluasi bagi peneliti pada siklus selanjutnya. Pada penelitian ini siklus dibatasi sebanyak dua kali jika siklus pertama tidak ada peningkatan. Metode Penelitian dapat dilihat pada Gambar 1. 


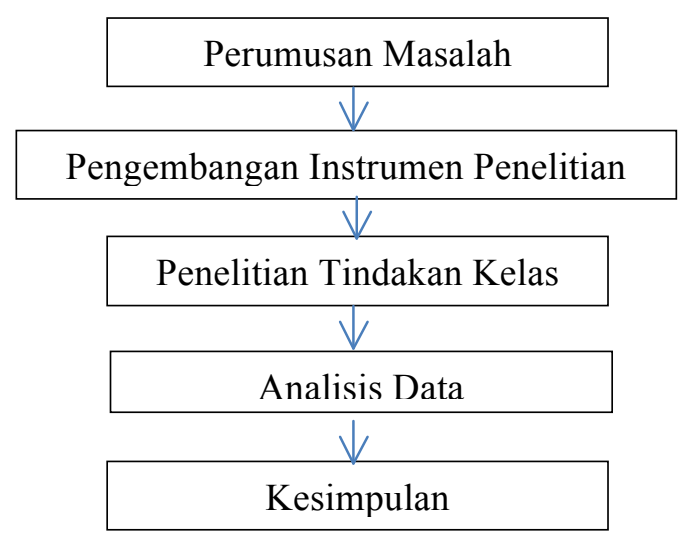

Gambar 1. Bagan Alir Penelitian Pembelajaran Pendidikan Kewarganegaraan dan Persepsi Radikalisme

Dalam penelitian ini, peneliti merencanakan dua siklus dalam PTK, bila siklus pertama persepsi mahasiswa tidak mengalami perbaikan seperti pada Gambar 2.

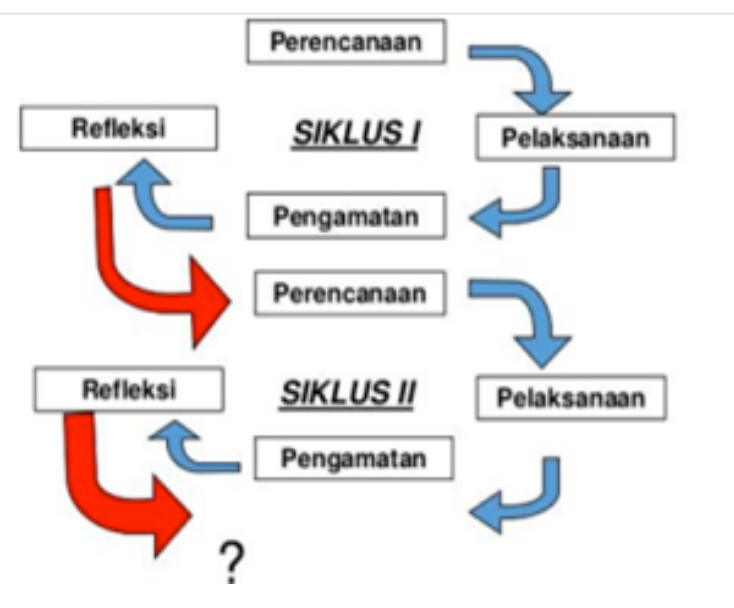

Gambar 2. Model Penelitian Tindakan Kelas (PTK)

Pada siklus pertama, mahasiswa akan diberikan (pretest) untuk mengetahui sejauh mana persepsi mahasiswa sebagai responden penelitian sebelum diberikan pembelajaran Pendidikan Pancasila pokok bahasan Pancasila Sebagai Ideologi. Langkah selanjutnya adalah proses pembelajaran interaktif yang dilakukan mahasiswa dan dosen pada Mata kuliah Pendidikan Pancasila. Mahasiswa dibagi menjadi beberapa kelompok dan diberikan buku ajar kemudian dilakukan diskusi pada masing-masing kelompok. Tahap selanjutnya adalah dosen memberikan tes kepada mahasiswa setelah seluruh rangkaian pelatihan berakhir (postest). Jika ada perubahan peningkatan dari hasil pretes maka dapat dikatakan mahasiswa mengalami perubahan pemahaman persepsi dengan menggolongkan menjadi 3 tipe pemahaman yaitu pemahaman yang cukup, baik, dan baik sekali.

Pengembangan kuesioner terbagi menjadi pernyataan negatif dan pernyatan positif. Skor untuk pernyataan positif bernilai 4 untuk jawaban sangat setuju, bernilai 3 untuk jawaban setuju, bernilai 2 untuk jawaban tidak setuju, dan bernilai 1 untuk jawaban sangat tidak setuju. Sedangkan skor untuk pernyataan negatif bernilai 1 untuk jawaban sangat setuju, bernilai 2 untuk jawaban setuju, bernilai 3 untuk jawaban tidak setuju, bernilai 4 untuk jawaban sangat tidak setuju.

Pengembangan kuesioner juga didasarkan pada tiga aspek yaitu definisi radikalisme, tujuan radikalisme, dan akibat radikalisme. Penilaian persepsi diukur melalui total skor yang didapatkan oleh masing-masing mahasiswa dengan nilai skor minimum 1 dan nilai skor maksimum 4 pada 15 butir item, sehingga didapatkan skor inventori seperti pada Tabel 1. 
Jurnal Pendidikan Kewarganegaraan

Vol. 5 No. 2 September 2018

Tabel 1. Skala Inventori Persepsi Mahasiswa terhadap Radikalisme

\begin{tabular}{cc}
\hline $\begin{array}{c}\text { Interval Total } \\
\text { Skor Mahasiswa }\end{array}$ & Kategori \\
\hline $15-30$ & Cukup \\
$31-45$ & Baik \\
$46-60$ & Sangat Baik \\
\hline
\end{tabular}

Sumber: Data sekunder yang diolah, Tahun 2018

Menurut Arikunto (2006) populasi adalah keseluruhan subjek penelitian. Populasi dalam penelitian ini adalah mahasiswa tahun pertama Program Stdui Teknologi Pengolahan Hasil Peternakan yang memiliki jumlah kurang lebih 100 mahasiswa. Batasan Kuesioner yang diberikan sejumlah 15 pernyataan karena jumlah mahasiswa baru TPHT semester 2 kurang lebih 120 mahasiswa. Sesuai dengan ketentuan untuk kuesioner yang diberikan 6 kali dari pernyataan.

Data yang digunakan dalam penelitian ini adalah data yang diperoleh dari lembar pretest dan postest yang berupa kuesioner dengan skala likert 4 tingkatan dengan 15 pernyataan. diberikan kepada mahasiswa bertujuan untuk mengetahui pemahaman mahasiswa mengenai radikalisme di Era Globalisasi program studi TPHT. Melalui teknik pengumpulan data yaitu dengan menggunakan teknik observasi dan tes. Teknik observasi digunakan untuk mengumpulkan data awal yang berkenaan dengan penelitian yang akan dilakukan serta pada proses pembelajaran. Arikunto (2006) mengatakan dalam menggunakan metode observasi cara yang paling efektif adalah melengkapinya dengan format atau blanko pengamatan sebagai instrumen. Observasi dalam penelitian ini dilakukan untuk mendapatkan data tentang aktivitas mahasiswa selama proses kegiatan belajar mengajar, teknik terdahulu yang digunakan dalam materi Pancasila sebagai Ideologi Negara. Sementara itu, yang dilakukan adalah untuk mengetahui tingkat keberhasilan yang telah dicapai mahasiswa selama proses belajar. Data kualitatif dapat diperoleh dari pengamatan mahasiswa saat pembelajaran sedang berlangsung sesuai indikator observasi yang telah disusun kemudian dipersentasikan peningkatan pada setiap pertemuan.

Berdasarkan salah satu karakteristik PTK, yaitu pengolahan datanya hanya menuntut penggunaan statistik yang sederhana, maka dalam penelitian ini pun tidak akan menggunakan pendekatan statistik yang terlalu rumit. Untuk melihat tingkat keberhasilan mahasiswa dan dosen dalam melaksanakan proses pembelajaran digunkan 5 kategori yaitu dapat dilihat pada Tabel 2 .

Tabel 2. Kategori Hasil Observasi Pembelajaran Mata Kuliah Pancasila

\begin{tabular}{cc}
\hline $\begin{array}{c}\text { Interval Total Skor } \\
\text { Observasi }\end{array}$ & Kategori \\
\hline $23-27$ & Sangat Baik \\
$19-22$ & Baik \\
$15-18$ & Cukup \\
$11-14$ & Kurang \\
$7-10$ & Gagal \\
\hline
\end{tabular}

Sumber: Data sekunder yang diolah, Tahun 2018

Penilaian tingkat keberhasilan pembelajaran dapat diukur dari total skor yang melalui perhitungan untuk skor maksimal maka diberikan skor 4 pada setiap pernyataan sedangkan untuk skor 
Jurnal Pendidikan Kewarganegaraan

Vol. 5 No. 2 September 2018
Journal of Civics and Education Studies p-ISSN 2302-0865 | e-ISSN 2621-346X minimal diberikan skor 1 dengan jumlah pernyataan observasi sebanyak 7 .

Tes pernyataan (kuesioner) untuk menguji tingkat pengetahuan mahasiswa (pretes) akan diberikan pada awal pembelajaran dan juga pertanyaan evaluasi akhir (postes) setelah pembelajaran Pendidikan Pancasila. Dari hasil perbandingan pretes dan postes ini akan terlihat apakah pembelajaran Pancasila dapat meningkatkan pemahaman mahasiswa mengenai radikalisme di Era Globalisasi.

Perbandingan kedua tes menggunakan rumus berikut uji dua sampel berpasangan. Jika $\mathrm{X}$ adalah variabel random berdistribusi normal dengan rata-rata pada sebelum dan sesudah perlakuan tertentu pada sampel yang sama dan varians tidak diketahui maka menggunakan uji $\mathrm{T}$ Dua sampel berpasangan. Hipotesis yang akan diuji adalah:

$\mathrm{H}_{0}: \mu_{1}=\mu_{2}$ $\mathrm{H}_{1}: \mu_{1} \neq \mu_{2}$

Dengan kriteria uji tolak $\mathrm{H}_{0}$ jika probabilitas kurang dari 0,05 dimana $\mu_{1}$ adalah rata-rata dari skor pre test dan $\mu_{2}$ adalah rata-rata dari skor post test. Uji ini akan dianalisis dengan software SPSS (Yasmin, 2009).

\section{Hasil dan Pembahasan}

$\begin{array}{ccr}\text { Proses } & \text { penelitian } & \text { hubungan } \\ \text { Pembelajaran } & \text { Pancasila } & \text { terhadap }\end{array}$ perubahan persepsi mahasiswa terhadap radikalisme dimulai dengan tahap pengembangan kuesioner sebagai alat pengukuran persepsi. Pengembangan kuesioner diawali dengan membagi pernyataan kedalam tiga kategori yaitu definisi radikalisme, tujuan radikalisme, dan akibat radikalisme. Penyebaran butir instrumen dapat dilihat pada Tabel 3.

Tabel 3. Kisi - Kisi Kuesioner/Instrumen Pengukuran Persepsi

\begin{tabular}{lc}
\hline \multicolumn{1}{c}{ Aspek } & \multicolumn{1}{c}{$\begin{array}{c}\text { Nomor Butir } \\
\text { Pernyataan }\end{array}$} \\
\hline $\begin{array}{l}\text { Definisi } \\
\text { Radikalisme } \\
\text { Tujuan } \\
\text { Radikalisme }\end{array}$ & $3,4,5,9,10,13$ \\
Akibat \\
Radikalisme
\end{tabular}

Setelah dikategorikan dalam tiga aspek kemudian kuesioner dibagi menjadi dua pernyataan yaitu pernyataan positif dan pernyataan negatif. Pernyataan negatif disusun lebih banyak dikarenakan mahasiswa lebih mengenal radikalisme sebagai sesuatu hal yang negatif. Sehingga untuk memudahkan pemahaman radikalisme, kuesioner persepsi mahasiswa terhadap radikalisme tersebar pada Tabel 4.

Tabel 4. Jenis Pernyataan pada Instrumen Pengukuran Persepsi

\begin{tabular}{|c|c|}
\hline $\begin{array}{c}\text { Jenis } \\
\text { Pernyataan }\end{array}$ & $\begin{array}{c}\text { Nomor Butir } \\
\text { Pernyataan }\end{array}$ \\
\hline $\begin{array}{l}\text { Pernyataan } \\
\text { Positif }\end{array}$ & $2,8,9,11,12$ \\
\hline $\begin{array}{l}\text { Pernyataan } \\
\text { Negatif }\end{array}$ & $\begin{array}{l}1,3,4,5,6,7,10 \\
13,14,15\end{array}$ \\
\hline
\end{tabular}

Sumber: Data primer yang diolah, Tahun 2018

Setelah kuesioner pengukuran persepsi selesai disusun, dilakukan proses validasi oleh dua orang validator. 
Validator menilai dari dua aspek yaitu aspek bahasa dan aspek isi. Aspek bahasa yaitu kesesuaian bahasa yang digunakan dalam pernyataan dengan tingkat kemampuan bahasa mahasiswa.
Sedangkan aspek isi dilihat kesesuaian pernyataan dengan kategori yang dibuat. Hasil dari validitas oleh validator dapat dilihat pada Tabel 5 .

\begin{tabular}{|c|c|c|}
\hline Validator & $\begin{array}{c}\text { Validitas } \\
\text { Bahasa }\end{array}$ & Validitas Isi \\
\hline Validator 1 & 13 & 15 \\
\hline Validator 2 & 14 & 13 \\
\hline
\end{tabular}

Sumber: Data primer yang diolah, Tahun 2018

Hasil dari penyebaran kuesioner terhadap radikalisme dan $41 \%$ mahasiswa kepada 91 mahasiswa pada pretest terbagi memiliki persepsi yang baik terhadap menjadi dua yaitu sebesar $59 \%$ mahasiswa radikalisme. Secara kategori dpat dilihat memiliki persepsi yang sangat baik pada Tabel 6 .

Tabel 6. Jumlah Mahasiswa pada Masing-Masing Skala Inventori

\begin{tabular}{clc}
\hline Aspek & Skala Inventori & $\begin{array}{c}\text { Jumlah Mahasiswa Tanpa } \\
\text { Skor 1 dan 2 }\end{array}$ \\
\hline Definisi Radikalisme & Tidak Memahami & 0 \\
& Cukup Memahami & 3 \\
& Sangat Memahami & 19 \\
Tujuan Radikalisme & Tidak Memahami & 0 \\
& Cukup Memahami & 10 \\
& Sangat Memahami & 47 \\
Akibat Radikalisme & Tidak Memahami & 0 \\
& Cukup Memahami & 6 \\
& Sangat Memahami & 41 \\
\hline
\end{tabular}

Sumber: Data primer yang diolah, Tahun 2018

Berdasarkan Tabel 6 dapat diketahui dari ketiga kategori sebanyak $21 \%$ mahasiswa memahami definisi radikalisme, $52 \%$ mahasiswa memahami tujuan radikalisme, dan $42 \%$ memahami akibat radikalisme. Dari hasil tersebut dapat diketahui lebih dari separuh mahasiswa Program Studi TPHT yang masih belum memahami definisi dan akibat radikalisme.
Setelah dilakukan pretest kemudian dilakukan proses pembelajaran Mata Kuliah Pendidikan Pancasila. Proses pembelajaran Mata Kuliah Pancasila menggunakan metode kooperatif. Dosen menjelaskan materi secara singkat kemudian dibagi kelompok dan mahasiswa mendiskusikan pokok bahasan Radikalisme dan Terorisme. Hasil dari pembelajaran Mata kuliah Pancasila pada keempat kelas dengan skor terendahnya terlihat pada Tabel 7 di bawah ini. 
Tabel 7. Hasil Observasi Pembelajaran Mata Kuliah Pancasila

\begin{tabular}{|c|c|c|c|c|c|}
\hline \multirow[t]{2}{*}{ No } & \multirow[t]{2}{*}{ Aspek yang Diamati } & \multicolumn{3}{|c|}{ Skor } & \multirow[b]{2}{*}{4} \\
\hline & & 1 & 2 & 3 & \\
\hline 1 & $\begin{array}{l}\text { Mahasiswa memberikan respon } \\
\text { positif terhadap pembelajaran }\end{array}$ & & & $\mathrm{V}$ & \\
\hline 2 & $\begin{array}{l}\text { Mahasiswa memberikan perhatian pada } \\
\text { penjelasan dosen }\end{array}$ & & & & $\mathrm{V}$ \\
\hline 3 & Mahasiswa mengajukan pertanyaan & & $\mathrm{V}$ & & \\
\hline 4 & Mahasiswa mengajukan pendapat & & & $\mathrm{V}$ & \\
\hline 5 & Mahaiswa menjawab pertanyaan dosen & & & & $\mathrm{V}$ \\
\hline 6 & $\begin{array}{l}\text { Mahasiswa mengerjakan tugas yang } \\
\text { diberikan dosen dengan serius }\end{array}$ & & & & $\mathrm{V}$ \\
\hline 7 & $\begin{array}{l}\text { Mahasiswa mengikuti pembelajaran } \\
\text { hingga akhir }\end{array}$ & & & & $\mathrm{V}$ \\
\hline
\end{tabular}

Sumber: Data primer yang diolah, Tahun 2018

Dari Tabel 7 tersebut menunjukkan Untuk mengetahui tingkat keberhasilan nilai total obsrvasi terendah sejumlah 24 dilakukan perhitungan persentase pada sehingga dapat dikategorikan pembelajaran Radikalisme dan terorisme sudah sangat baik pada keempat kelas. masing-masing kelas. Hasil perhitungan tingkat keberhasilan dapat dilihat pada Gambar 2.

\section{Persentase Tingkat Keberhasilan Pembelajaran Radikalisme di Kelas}

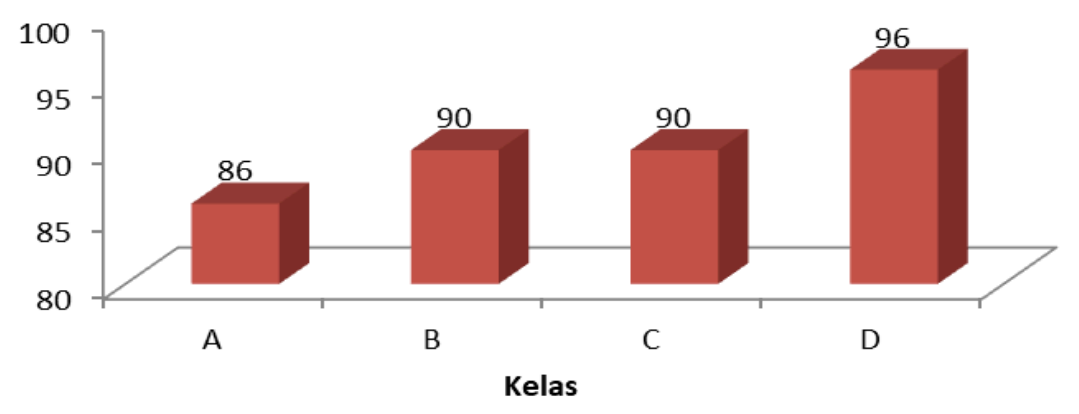

Gambar 2. Persentase Tingkat Keberhasilan Pembelajaran di Masing-Masing Kelas 
Hasil dari penyebaran kuesioner kepada 91 mahasiswa pada posttest terbagi menjadi dua yaitu sebesar $82 \%$ mahasiswa memiliki persepsi yang sangat baik terhadap radikalisme dan $18 \%$ mahasiswa memiliki persepsi yang baik terhadap radikalisme. Secara kategori dpat dilihat pada Tabel 8 .

Tabel 8. Jumlah Mahasiswa pada Masing-Masing Skala Inventori

\begin{tabular}{clc}
\hline Aspek & Skala Inventori & $\begin{array}{c}\text { Jumlah Mahasiswa Tanpa Skor 1 } \\
\text { dan 2 }\end{array}$ \\
\hline Definisi Radikalisme & Tidak Memahami & 0 \\
& Cukup Memahami & 3 \\
& Sangat Memahami & 23 \\
Tujuan Radikalisme & Tidak Memahami & 0 \\
& Cukup Memahami & 9 \\
& Sangat Memahami & 60 \\
Akibat Radikalisme & Tidak Memahami & 0 \\
& Cukup Memahami & 6 \\
& Sangat Memahami & 41 \\
\hline
\end{tabular}

Sumber: Data primer yang diolah, Tahun 2018

Berdasarkan Tabel 8 dapat diketahui dari ketiga kategori sebanyak 25\% mahasiswa memahami definisi radikalisme, $60 \%$ mahasiswa memahami tujuan radikalisme, dan $45 \%$ memahami akibat radikalisme. Dari hasil tersebut dapat diketahui lebih dari separuh mahasiswa Program Studi TPHT yang masih belum memahami definisi dan akibat radikalisme.

Berikutnya untuk melihat hubungan antara Pembelajaran Pancasila khususnya Radikalisme dengan Persepsi Mahasiswa dilakukan analisis menggunakan Uji $\mathrm{T}$ dengan hasil dari Uji $\mathrm{T}$ Berpasangan seperti pada Tabel 9.

Tabel 9. Hasil Uji T Berpasangan

\begin{tabular}{cccc}
\hline & \multicolumn{3}{c}{ Paired Sample T Test } \\
\hline & $\mathrm{t}$ & $\mathrm{df}$ & Sig (2 Tailed) \\
Pair1 PreTest- & -5.692 & 90 & 0.000 \\
Posttesr & & & \\
\hline
\end{tabular}

Sumber : Data Primer yang diolah, Tahun 2018

Pada Tabel 9 dapat dilihat nilai signifikansi yang melebihi 0,05 sehingga hiotesis nol yang diajukan ditolak. Hal tersebut memberikan makna ada perbedaan rata-rata nilai sebelum dan sesudah pembelajaran.
Pada hasil post test dapat dilihat kategori mahasiswa yang memiliki persepsi sangat baik mengalami peningkatan yang awalnya $59 \%$ menjadi $81 \%$, sehingga siklus tidak berlanjut pada Siklus II. 
Jurnal Pendidikan Kewarganegaraan

Vol. 5 No. 2 September 2018

\section{Kesimpulan}

Kesimpulan dari penelitian ini yaitu adanya hubungan antara Pembelajaran Pancasila dengan persepsi mahasiswa mengenai radikalisme. Hal tersebut ditunjukkan peningkatan kategori persepsi mahasiswa sangat baik meningkat sebesar $22 \%$. Pada klasifikasi ketiga aspek persepsi diketahui mahasiswa masih cukup rendah dalam memahami definisi radikalisme. Dapat dimaknai mahasiswa TPHT belum mampu mengenali tindakan-tindakan yang tergolong radikalisme dan mengarah ketindakan terorisme.

\section{Referensi}

Arikunto, S. (2006). Prosedur Penelitian Suatu Pendekatan Praktik. Jakarta: Rineka Cipta.

Dirjen Pembelajaran dan Kemahasiswaan. (2016). Pendidikan Pancasila Untuk Perguruan Tinggi. Jakarta : Kemenristekdikti.

Harfin, M. Z. (2010). Fundamentalisme dan Upaya Deradikalisme Ayat AlQuran dan hadis. Jurnal Religi, Vol.13 No.1.
Journal of Civics and Education Studies p-ISSN 2302-0865 | e-ISSN 2621-346X

Kalibe, A. (2011). Upaya Peningkatan Keterampilan Membaca Pemahaman Melalui Penerapan Teknik Skema Pada SMP Negeri 24 Samarinda. Jurnal Eksis.

Mujani, S. (2007). Muslim Demokrat: Islam Budaya Demokrasi, dan Partisipasi Politik di Indonesia Pasca Orde Baru. Jakarta : Gramedia.

Subchan, W. (2005). Evaluasi Hasil Belajar Mahasiswa. Jember: Program Studi Pendidikan Biologi FKIP Universitas Jember.

Sukardi. (2004). Metodologi Penelitian Pendidikan. Yogyakarta: Bumi Aksara.

Sumbulah, U. (2010). Islam radikal dan Plularisme Agama. Jakarta : Balitbang RI.

Tim Penyusun. (2013). Mata Ajar Mata Kuliah Pendidikan Pancasila. Jakarta : Dirjen Pendidikan Tinggi Kemendikbud.

Yamin, S., \& Kurniawan, H. (2009). SPSS Complete Teknik Analisis Terlengkap dengan Software SPSS. Jakarta: Salemba Infotek. 